\title{
The Kidney as an Endocrine Organ
}

\author{
Vinay Acharya, D.O.; Juan Olivero, M.D. \\ HOUSTON METHODIST HOSPITAL, HOUSTON, TEXAS
}

The column in this issue is supplied by Vinay Acharya, D.O., and Juan Jose Olivero, M.D. Dr. Acharya is a nephrology fellow at Houston Methodist Hospital. He earned his Doctor of Osteopathic Medicine degree at Arizona College of Osteopathic Medicine and completed an internal medicine residency at Houston Methodist Hospital. Dr. Olivero is a nephrologist at Houston Methodist Hospital and a member of the hospital's Nephrology Training Program. He obtained his medical degree from the University of San Carlos School of Medicine in Guatemala and completed his residency and nephrology fellowship at Baylor College of Medicine in Houston, Texas.

If one were to poll a group of medical professionals with the question "What are the top five roles of the kidney?" it is fairly safe to assume that the top four roles would prompt similar responses: controlling volume status, maintaining acid-base balance, ensuring electrolyte homeostasis, and eliminating waste products. The fifth role, however, would likely elicit a new tier of answers that could be grouped into one important and often forgotten collection: renal endocrinology. This column reviews some of the well- and lesser-known endocrine functions of the kidney.

\section{RENIN PRODUCTION}

Renin is a protease that catalyzes the rate-limiting step of the renin-angiotensin system by cleaving angiotensinogen to angiotensin I. It is secreted from the juxtaglomerular cells through three main mechanisms: (1) baroreceptors in the afferent arteriole that sense a drop in arterial blood pressure, (2) a decreased concentration of sodium chloride at the macula densa, and (3) increased catecholamines that activate betaadrenergic receptors on juxtaglomerular cells. Angiotensin I is then converted by angiotensin-converting enzyme to angiotensin II, leading to increased antidiuretic hormone production, vasoconstriction, aldosterone secretion, sodium reabsorption, and water retention. ${ }^{1,2}$

\section{ERYTHROPOIETIN PRODUCTION}

Erythropoietin (EPO) is a hormone originating from fibroblasts in the renal cortex that regulates erythropoiesis, or red blood cell production. The driving force behind EPO production is hypoxia, which impedes inhibition of the EPO promotor GATA2 and stimulates EPO enhancers. ${ }^{3}$ EPO increases erythroid precursors and the number of cells capable of erythroid differentiation. ${ }^{4}$ However, with continued hypoxia, EPO levels will return to baseline. In 1983, a synthetic version of EPO was discovered. Injections of this synthetic erythropoietin allowed patients with chronic kidney disease to decrease their transfusion dependence and correct their anemia over a few weeks. $^{5}$

\section{VITAMIN D ACTIVATION}

Vitamin $D_{3}$ is a prohormone synthesized from the interaction between ultraviolet rays in sunlight and 7-dehydrocholesterol in the skin. Once synthesized, vitamin $D_{3}$ is hydroxylated in the liver to produce $25(\mathrm{OH}) \mathrm{D}_{3}$, which in turn is hydroxylated by 1-alpha hydroxylase (produced by the proximal tubule of the kidney) to 1 -alpha, $25(\mathrm{OH})_{2} \mathrm{D}_{3}$, the active form of vitamin D. Activated vitamin D plays a large role in calcium and phosphorus homeostasis, interacting with the small intestine, parathyroid glands, bones, and kidneys. Vitamin D also plays a role in insulin secretion (by regulating the adaptive and innate immune system), and in blood pressure regulation. In patients with chronic kidney disease, the kidney's ability to hydroxylate $25(\mathrm{OH}) \mathrm{D}_{3}$ is reduced, which leads to secondary hyperparathyroidism in an attempt to maintain calcium and phosphorus homeostasis. ${ }^{6}$

\section{PROSTAGLANDIN METABOLISM}

Prostaglandins are lipid compounds produced throughout the body that contribute to vasodilation and inflammation. In the kidney, prostaglandins are responsible for regulating vascular tone and salt and water homeostasis. Prostaglandin E2 (PGE2) and prostacyclin $\left(\mathrm{PGI}_{2}\right.$ ) are responsible for increasing renal blood flow despite a decreased effective circulating volume. Cyclooxygenase (COX) is an enzyme that is responsible for the rate-limiting step in PG synthesis. Thus, COX inhibitors exert their nephrotoxicity by decreasing the production of PGE2. In addition, PGE2 counteracts conditions with excessive sodium and water reabsorption by inhibiting the $\mathrm{Na}^{+} \mathrm{K}^{+}-2 \mathrm{Cl}^{-}$cotransporter in the thick ascending loop of Henle. ${ }^{7}$ 


\section{INSULIN METABOLISM}

Although both the liver and kidney play important roles in insulin metabolism, the kidney is the primary site of insulin clearance from the systemic circulation. This clearance occurs by two major mechanisms: proximal tubular reabsorption (99\%) and glomerular filtration. After proximal tubular reabsorption, insulin is endocytosed into endosomes and begins to degrade. Insulin fragments are delivered to lysosomes, where degradation is completed. In patients with renal failure, the insulin requirement is dramatically reduced due to decreased insulin degradation. Medications such as sulfonylureas run a very high risk for causing hypoglycemia in these patients because of decreased degradation of both insulin and the drug. ${ }^{8}$

\section{GASTRIN METABOLISM}

Gastrin, a hormone produced by the G cells of the stomach and duodenum, is responsible for stimulating secretion of gastric hydrochloric acid. Elevated levels of gastrin have been seen in both acute and chronic kidney disease, leading to the theory that the kidney is responsible for gastrin metabolism. This is supported by studies showing elevated levels of gastrin in animals with bilateral nephrectomy and normalization of gastrin levels in patients post kidney transplant. Davidson et al. found that roughly $30 \%$ of endogenous gastrin was inactivated by the kidney when measuring the difference between gastrin levels in the renal artery and renal vein. No significant amount of gastrin was excreted into the urine, suggesting catabolism by the kidney. ${ }^{9}$ The fact that gastrin is not adequately metabolized in patients with kidney disease could contribute to the substantially increased risk of peptic ulcer disease in this patient population. ${ }^{10}$

\section{PARATHYROID HORMONE METABOLISM}

Parathyroid hormone (PTH) is secreted by the chief cells of the parathyroid gland. PTH enhances bone resorption, calcium reabsorption in the kidney, and calcium absorption in the intestine and reduces phosphate reabsorption in the kidney. In chronic kidney disease, the kidney's decreased ability to excrete phosphorus and activate vitamin D leads to hypocalcemia and hyperphosphatemia, which causes increased PTH release and parathyroid hyperplasia. Elevated PTH has been shown to cause renal osteodystrophy, worsen soft tissue and vascular calcification, and decrease left ventricular ejection fraction. ${ }^{11}$

\section{GLUCONEOGENESIS}

Gluconeogenesis is one of the two ways glucose is released into circulation in the fasting state. It involves the formation of glucose-6-phosphate from lactate, glycerol, and amino acids, after which glucose-6-phosphatase hydrolyzes a phosphate group to create free glucose. Although we generally think of the liver as the main site of this reaction, the kidney also has the ability to carry out gluconeogenesis. The renal medulla is the site of glucose phosphorylation and glycolytic enzyme activity. The cells in the renal cortex possess glucose-6-phosphatase, enabling them to release free glucose into circulation. Interestingly, acidosis increases renal gluconeogenesis but decreases hepatic gluconeogenesis, highlighting the importance of renal free glucose generation and release in diabetic ketoacidosis. ${ }^{12}$

\section{THROMBOPOIETIN GENERATION}

Thrombopoietin (TPO) is a glycoprotein responsible for the production and activation of platelets. Although the liver is responsible for a majority of TPO production, the kidneyspecifically the cells of the proximal convoluted tubule-also produces a small amount. That being said, multiple studies have shown no decrease in TPO level in patients with end-stage renal disease..$^{13,14}$

\section{URODILATIN}

Brain natriuretic peptide (BNP) is a polypeptide released by myocytes in response to stretching of the ventricles. BNP secretion results in natriuresis and decreased systemic vascular resistance. Atrial natriuretic peptides (ANPs) are in the same family of polypeptides but are synthesized by different genes. The kidney produces a specific type of ANP called urodilatin ${ }^{15}$ that is synthesized in the tubular cells. Urodilatin inhibits sodium reabsorption and relaxes renal arterial smooth muscles, leading to diuresis and vasodilation of renal, coronary, and pulmonary vessels. High-sodium diets, acute normal saline volume expansion, and balloon dilation of the left atrium have all been shown to increase urodilatin excretion. Urodilatin, also known as the renal natriuretic peptide, is essential for maintaining sodium and water homeostasis. ${ }^{16}$

\section{REFERENCES}

1. Sparks MA, Crowley SD, Gurley SB, Mirotsou M, Coffman TM. Classical Renin-Angiotensin system in kidney physiology. Compr Physiol. 2014 July;4(3):1201-28.

2. Gilbert SJ, Weiner DE. National Kidney Foundation Primer on Kidney Diseases. 7th ed. Philadelphia: Elsevier; 2017. Chapter 1; Overview of Kidney Structure and Function; p. 2-18.

3. Jelkmann W. Regulation of erythropoietin production. J Physiol. 2011 Mar;589(Pt 6):1251-8. 
4. Ridley D, Dawkins F, Perlin E. Erythropoietin: a review. J Natl Med Assoc. 1994 Feb;86(2):129-35.

5. Adamson JW. The story of erythropoietin. In: Kaushansky K, Berliner N. 50 years in hematology: research that revolutionized patient care. Washington, DC: American Society of Hematology; 2008. p. 6.

6. Norman AW. From vitamin $D$ to hormone $D$ : fundamentals of the vitamin D endocrine system essential for good health. Am J Clin Nutr. 2008 Aug;88(2):491S-499S.

7. Kim GH. Renal effects of prostaglandins and cyclooxygenase- 2 inhibitors. Electrolyte Blood Press. 2008 Jun;6(1):35-41.

8. Duckworth WC, Bennett RG, Hamel FG. Insulin degradation: progress and potential. Endocr Rev. 1998 Oct;19(5):608-24.

9. Davidson WD, Springberg PD, Falkinburg NR. Renal extraction and excretion of endogenous gastrin in the dog. Gastroenterol. 1973 May;64(5):955-61.

10. Liang CC, Muo CH, Wang IK, et al. Peptic ulcer disease risk in chronic kidney disease: ten-year incidence, ulcer location, and ulcerogenic effect of medications. PLoS One. 2014 Feb 3;9(2):e87952.
11. Joy MS, Karagiannis PC, Peyerl FW. Outcomes of secondary hyperparathyroidism in chronic kidney disease and the direct costs of treatment. J Manag Care Pharm. 2007 Jun;13(5):397-411.

12. Gerich JE, Meyer C, Woerle HJ, Stumvoll M. Renal gluconeogenesis: its importance in human glucose homeostasis. Diabetes Care. 2001 Feb;24(2):382-91.

13. Sungaran R, Markovic B, Chong BH. Localization and regulation of thrombopoietin mRNa expression in human kidney, liver, bone marrow, and spleen using in situ hybridization. Blood. 1997 Jan 1;89(1):101-7.

14. Stockelberg D, Andersson P, Björnsson E, Björk S, Wadenvik H. Plasma thrombopoietin levels in liver cirrhosis and kidney failure. J Intern Med. 1999 Nov;246(5):471-5.

15. Vesely DL. Natriuretic peptides and acute renal failure. Am J Physiol Renal Physiol. 2003 Aug;285(2):F167-77.

16. Forssmann W, Meyer M, Forssmann K. The renal urodilatin system: clinical implications. Cardiovasc Res. 2001 Aug 15;51(3):450-62. 